\title{
Surface Segregation of Chromium in a Copper-Chromium Alloy and its Effect on Formation of a Native Oxide Layer
}

\author{
Shigeru Suzuki, Yukio Ishikawa*, Minoru Isshiki and Yoshio Waseda \\ Institute of Multidisciplinary Research for Advanced Materials, Tohoku University, Sendai 980-8577, Japan
}

\begin{abstract}
Angle-resolved X-ray photoelectron spectroscopy (AR-XPS) has been used for studying the surface segregation of chromium in a copper0.4 mass $\%$ chromium alloy. The influence of the chromium segregation on native oxide layers formed on the surface in this alloy has also been studied. According to a simple layered model assuming thin homogeneous layers, the average surface concentration chromium was found to increase up to about 15 at $\%$ on the alloy surface by annealing up to about $1000 \mathrm{~K}$ under ultra high vacuum. The AR-XPS results for the alloy surface with chromium segregation, which was exposed to air, showed that the growth of the native oxide layer of copper was not significantly suppressed by segregated chromium. This small influence of chromium segregation on the native oxide layer is considered to result from the relatively high oxidation rate of copper and the microscopic heterogeneity of chromium segregation on the alloy surface.
\end{abstract}

(Received May 8, 2002; Accepted August 5, 2002)

Keywords: copper-chromium alloy, surface segregation, angle resolved $x$-ray photoelectron spectroscopy, oxidation

\section{Introduction}

Copper base alloys are important materials used in microelectronics, because of their high electrical conductivity. However, the surface of copper base alloys appears to be unstable, as exemplified in the growth of oxide layers on the surface of these alloys at relatively low temperatures. Therefore, the oxidation of copper base alloys for lead frames have been investigated, ${ }^{1,2)}$ while the dynamic oxidation of copper base alloys at high temperature has also been studied. ${ }^{3)}$ Although the surface behavior of copper base alloys is of great importance in their application, microscopic characteristic features of the oxidation of copper base alloys are not understood so much. One of the reasons is as follows; the oxidation of these alloys involves complicated phenomena, such as enrichment and oxidation of small amounts of alloying elements in copper base alloys.

The present authors have studied the initial oxidation of ultra high-purity copper, which was prepared in an anionexchange separation method, ${ }^{4)}$ by angle-resolved X-ray photoelectron spectroscopy (AR-XPS). ${ }^{5 \text { ) }}$ These results showed that the thickness of native oxide layers formed on the copper surface at room temperature is nanometer of magnitude, and the thickness of the oxide layers gradually increases with increasing exposure time even at room temperature. On the other hand, the growth of native oxide layers of iron was found to stop at room temperature, ${ }^{5)}$ and chromium segregated on the iron surface reduces the growth of native oxide layers in iron base alloys. ${ }^{6}$ ) This characteristic feature of chromium is contrary to the influence of surface segregation of copper on native oxide layers formed on the iron surface; copper does not suppress growth of a iron native oxide layer. ${ }^{7)}$ Thus, it is of great interest whether the chromium segregation occurs in copper base alloys or not, and the chromium segregation influences the formation of native oxide layers, if it occurs. These backgrounds prompt us to study a change in the surface composition of a copper-chromium alloy annealed at high temperature, and the variation of a native oxide layer by inducing the change in the surface composition. These results are believed to give important information in discussing the surface stability of copper base alloys for electrical connector and lead frame.

\section{Experimental}

A button of a copper- 0.41 mass $\%$ chromium alloy, which is referred to as $\mathrm{Cu}-0.4 \% \mathrm{Cr}$ alloy hereafter, was prepared from $6 \mathrm{~N}$ copper and $4 \mathrm{~N}$ chromium by arc melting. The button was cold rolled to $0.5 \mathrm{~mm}$ thick sheets, which were cut to about $10 \mathrm{~mm}$ square. They were annealed at about $1100 \mathrm{~K}$ for $24 \mathrm{~h}$ in hydrogen gas and quenched to room temperature. By this treatment, most of chromium is considered to dissolve in the copper matrix. These samples were polished electrochemically in aqueous solution with $60 \%$ phosphoric acid. Finally, the sample surface was fully sputtered by argon ions of $3 \mathrm{keV}$ to remove a surface layer before XPS measurements.

XPS measurements were performed in the same manner of the previous work. ${ }^{5,8)}$ Only some essential points are given below. An XPS apparatus, PHI-5600, with a computer aided tilting state was used, and the incident X-ray was $\mathrm{Mg} K \alpha$ radiation. $\mathrm{Cu} 2 \mathrm{p}, \mathrm{Cr} 2 \mathrm{p}, \mathrm{O} 1 \mathrm{~s}$ and $\mathrm{C} 1 \mathrm{~s}$ XPS spectra were recorded, and their relative sensitivity factors given in the spectrometer were for quantification. The take-off angle, which is defined as the angle between the direction of an analyzer and the sample plane, was changed from $0.262 \mathrm{rad}$ (15 degree) to $1.31 \mathrm{rad}$ (75 degree) in the AR-XPS measurements. Angle resolved X-ray excited Auger electron spectra (AR-XAES) were also measured for studying the chemical state of copper. ${ }^{9)}$ Ordinary XPS spectra were obtained in the take-off angle of $0.786 \mathrm{rad}$ (45 degree).

The samples were annealed under an ultra high vacuum, and the chromium segregation on the sample surface was analyzed. A native oxide layer formed on the sample surface by exposing it to air was also evaluated. The thickness of surface segregated layer and native oxide layer was evaluated by AR-XPS. $5,6,8)$ 


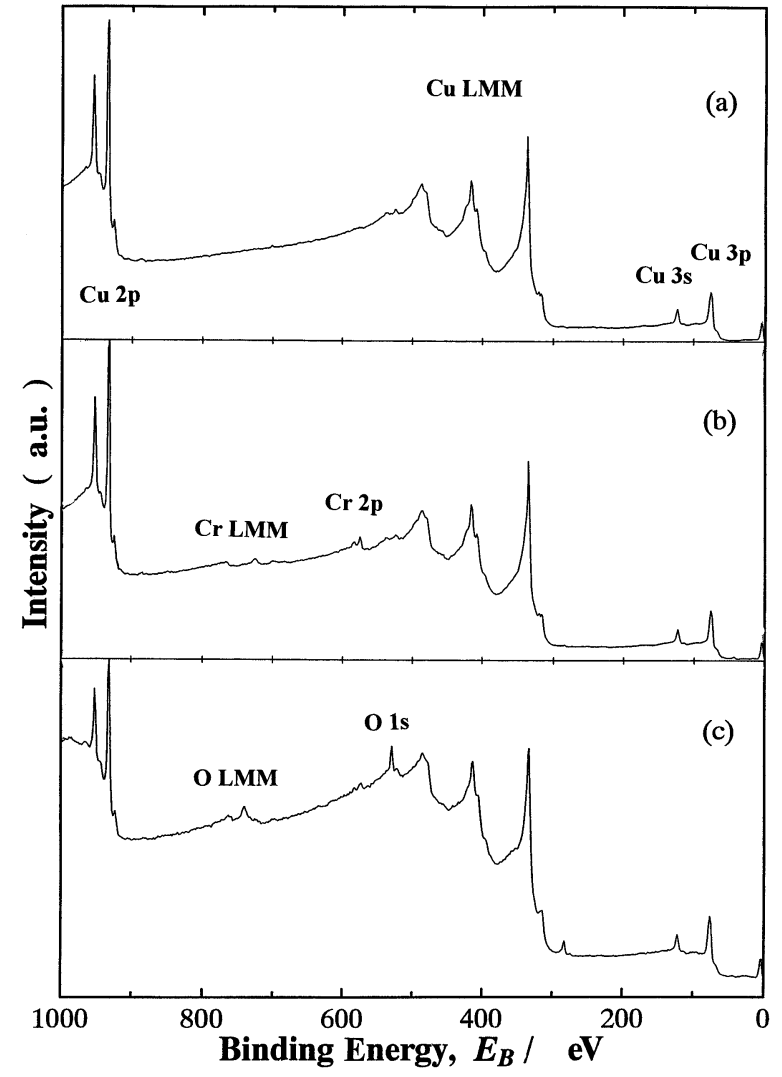

Fig. 1 XPS wide spectra from the surface (a) sputter cleaned, (b) annealed at $973 \mathrm{~K}$, and (c) subsequently exposed to air in $\mathrm{Cu}-0.4 \% \mathrm{Cr}$ alloy.

\section{Results and Discussion}

\subsection{Surface segregation of chromium}

Figures 1(a) shows a wide XPS spectrum from the sputtercleaned surface of $\mathrm{Cu}-0.4 \% \mathrm{Cr}$ alloy, which was obtained in the take-off angle of $0.786 \mathrm{rad}$. In this spectrum, chromium peak is little observed because of the low bulk concentration of chromium. However, XPS and XAES peaks of chromium were found on the surface of the sample annealed in the temperatures over $600 \mathrm{~K}$. Figures 1(b) describes a wide XPS spectrum from the surface of $\mathrm{Cu}-0.4 \% \mathrm{Cr}$ alloy annealed at $973 \mathrm{~K}$ for $600 \mathrm{~s}$. The Cr 2p XPS peaks and Cr LMM XAES peaks are observed by annealing, indicating that chromium is segregated at the sample surface by annealing at high temperatures. An XPS spectrum form the sample surface with chromium segregation, which was subsequently exposed to air for $600 \mathrm{~s}$, is shown in Fig. 1(c). Since the sample surface was oxidized by air exposure, $\mathrm{O}$ 1s XPS peaks and $\mathrm{O}$ LMM XAES peaks are superimposed on the spectrum of the chromium segregated sample. Characteristic features of these oxide layers will be described in the following section.

Since the chromium segregated layer on the surface of $\mathrm{Cu}-$ $0.4 \% \mathrm{Cr}$ alloy is very thin, AR-XPS can be applied for analyzing the segregated layer non-destructively. Figure 2 shows the concentration of copper and chromium obtained from XPS peak intensities versus the take-off angle in $\mathrm{Cu}-0.4 \% \mathrm{Cr}$ alloy, which was annealed at $973 \mathrm{~K}$ for $600 \mathrm{~s}$ under ultra high vacuum. Experimental data are plotted as marks, while calculated results on the basis of a layered structure model ${ }^{6)}$ are shown as lines. From comparison of these experimental and

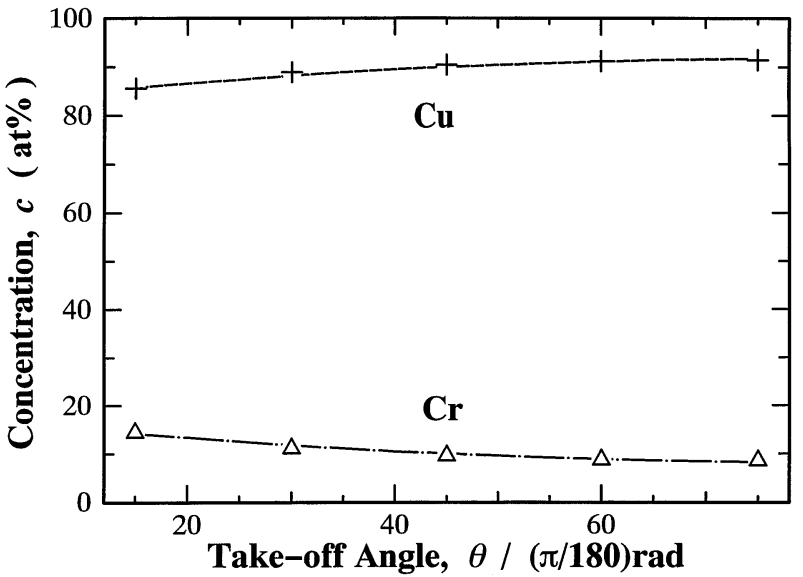

Fig. 2 The concentration of copper and chromium versus the take-off angle in $\mathrm{Cu}-0.4 \% \mathrm{Cr}$ alloy, which was annealed at $973 \mathrm{~K}$ under ultra high vacuum. Experimental data and calculated results are denoted by marks and lines, respectively.

calculated results, the thickness of the chromium segregated layer and the average concentration of chromium in the layer is about $0.8 \mathrm{~nm}$ and 15 at\%, respectively. Roughly speaking, the chromium concentration in the surface layer corresponds to the value measured at the take-off angle of $0.262 \mathrm{rad}$., and the thickness can be calculated form the decrease of the concentration measured at higher take-off angles. Since the bulk composition of chromium is 0.41 mass $\%(0.53$ at $\%)$, the enrichment ratio of chromium at the surface is about twentyeight. This enrichment value is higher than that for chromium segregated in iron base alloys, and chromium is considered to a surface-active element in copper base alloys. The thickness value of the chromium segregated layer, about $0.8 \mathrm{~nm}$, suggests that the chromium segregation may be extended to a few atomic layer, and therefore chromium in the segregated layer is considered to behave as bulk. Then, the chromium concentration, 15 at $\%$, in the segregated layer implies that chromium may be precipitated as a second phase, as inferred from the binary alloy phase diagram. ${ }^{10)}$ However, since the take-off angle dependence of the chromium concentration, as shown in Fig. 2, suggests the segregated layer is limited in a very thin surface region, such chromium precipitation appears to be hardly distinguished with the surface segregation induced by the surface energy.

\subsection{Native oxide layer}

Native oxide layers formed on the surface of $\mathrm{Cu}-0.4 \% \mathrm{Cr}$ alloy with segregation was analyzed by AR-XPS, in order to study the influence of the chromium segregation on the oxide layer. The effective thickness of native oxide layers was evaluated in the same model reported previously. ${ }^{5)}$ In this model, $\mathrm{a} \mathrm{Cu}_{2} \mathrm{O}$ layer is assumed to form on the surface of copper. Figure 3 shows the concentration of copper, chromium, oxygen and carbon versus the take-off angle in $\mathrm{Cu}-0.4 \% \mathrm{Cr}$ alloy with chromium segregation, which was exposed to air for $4.2 \times 10^{5} \mathrm{~s}$. Experimental and calculated results are denoted by mark and line, respectively. The thickness values of the oxide layer and contaminated layer were estimated to be about $3 \mathrm{~nm}$ and $0.5 \mathrm{~nm}$, respectively. The thickness of this oxide layer is comparable to that of an oxide layer formed on 


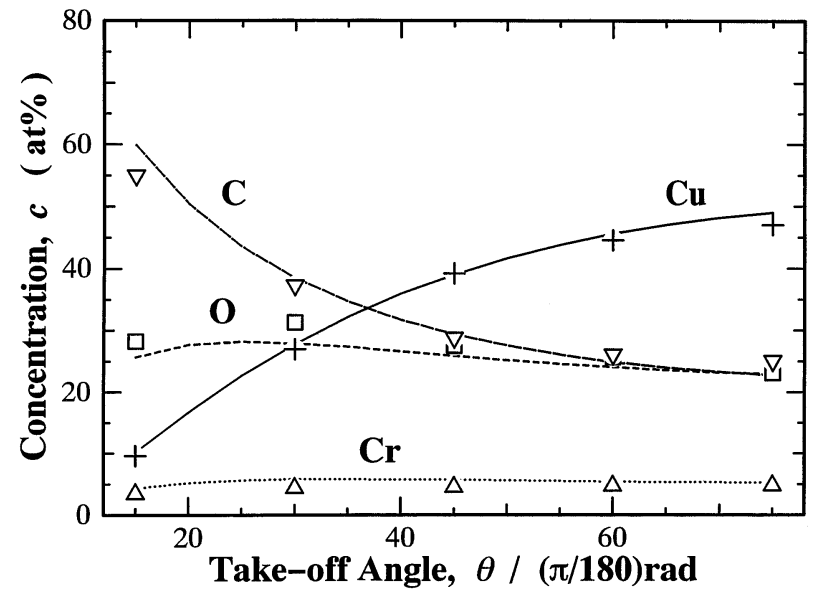

Fig. 3 The concentration of copper, chromium, oxygen and carbon versus the take-off angle in $\mathrm{Cu}-0.4 \% \mathrm{Cr}$ alloy, which was exposed to air for $4.2 \times 10^{5} \mathrm{~s}$ after segregation. Experimental date and calculated results are denoted by marks and lines, respectively.

the high-purity copper, ${ }^{5)}$ indicating that the chromium segregation does not appear to suppress the growth of the oxide layer.

However, small changes in the $\mathrm{Cu} 2 \mathrm{p}$ XPS spectra by chromium segregation were observed in this sample. Figures 4(a), (b), (c), (d) and (e) show Cu 2p AR-XPS spectra obtained in the take-off angle of 0.262, 0.524, 0.786, 1.05 and $1.31 \mathrm{rad}$ for $\mathrm{Cu}-0.4 \% \mathrm{Cr}$ exposed to air for $4.2 \times 10^{5} \mathrm{~s}$, respectively. For comparison, $\mathrm{Cu} 2 \mathrm{p}$ XPS spectrum obtained in the small take-off angle of 0.262 rad for high-purity copper exposed to air for $4.2 \times 10^{5} \mathrm{~s}$ is given in Fig. 4(f). ${ }^{5)}$ Although it should be noted that a difference of the peak position between $\mathrm{Cu}^{+}\left(\mathrm{Cu} 2 \mathrm{p}_{3 / 2}: 932.6 \mathrm{eV}\right)$ and $\mathrm{Cu}^{0}\left(\mathrm{Cu} \mathrm{2} \mathrm{p}_{3 / 2}: 932.7 \mathrm{eV}\right)$ is small, ${ }^{11)}$ a $\mathrm{CuO}$ layer is consider to mainly cover the surface of $\mathrm{Cu}-0.4 \% \mathrm{Cr}$ exposed to air. On the other hand, an oxide layer containing $\mathrm{Cu}^{2+}\left(\mathrm{Cu} 2 \mathrm{p}_{3 / 2}\right.$ : $\left.935.6 \mathrm{eV}\right)$, presumably $\mathrm{CuO}$, forms at the top surface layer of high-purity copper, as shown in Fig. 4(f). ${ }^{5)}$ This fact implies that the chromium segregation may somewhat suppress the formation of $\mathrm{CuO}$ on the surface of copper.

Chemical changes in oxide layers formed on the surface of $\mathrm{Cu}-0.4 \% \mathrm{Cr}$ alloy with the surface segregation of chromium were studied using $\mathrm{Cu}$ LMM spectra. Figures 5(a), (b), (c), (d) and (e) show $\mathrm{Cu} \mathrm{L}_{3} \mathrm{M}_{45} \mathrm{M}_{45}$ AR-XAES spectra obtained in the take-off angle of $0.262,0.524,0.786,1.05$ and $1.31 \mathrm{rad}$ for $\mathrm{Cu}-0.4 \% \mathrm{Cr}$ with the chromium segregation, which was exposed to air for $4.2 \times 10^{5} \mathrm{~s}$. A Cu L ${ }_{3} \mathrm{M}_{45} \mathrm{M}_{45}$ XAES spectrum from metallic copper is given in Fig. 5(f), for comparison. The spectra of $\mathrm{Cu} \mathrm{L}_{3} \mathrm{M}_{45} \mathrm{M}_{45}$ AR-XAES for the sample exposed to air could be assigned to the signals from copper oxide $\left(\mathrm{Cu}^{+}: 916.2 \mathrm{eV}\right)$ and metallic copper $\left(\mathrm{Cu}^{0}: 918.6 \mathrm{eV}\right)$. Since a peak due to $\mathrm{Cu}^{0}$ appears to increase with increasing take-off angle in this sample as shown in Fig. 5, it may safely be said that an oxide layer with $\mathrm{Cu}^{+}$covers the metallic copper. This is consistent with the compositional results of the take-off dependence of the measured concentration as shown in Fig. 3, suggesting that metallic copper is covered be an oxide layer.

In addition, AR-XPS was used for analyzing changes in the chemical state of surface segregated chromium by air ex-

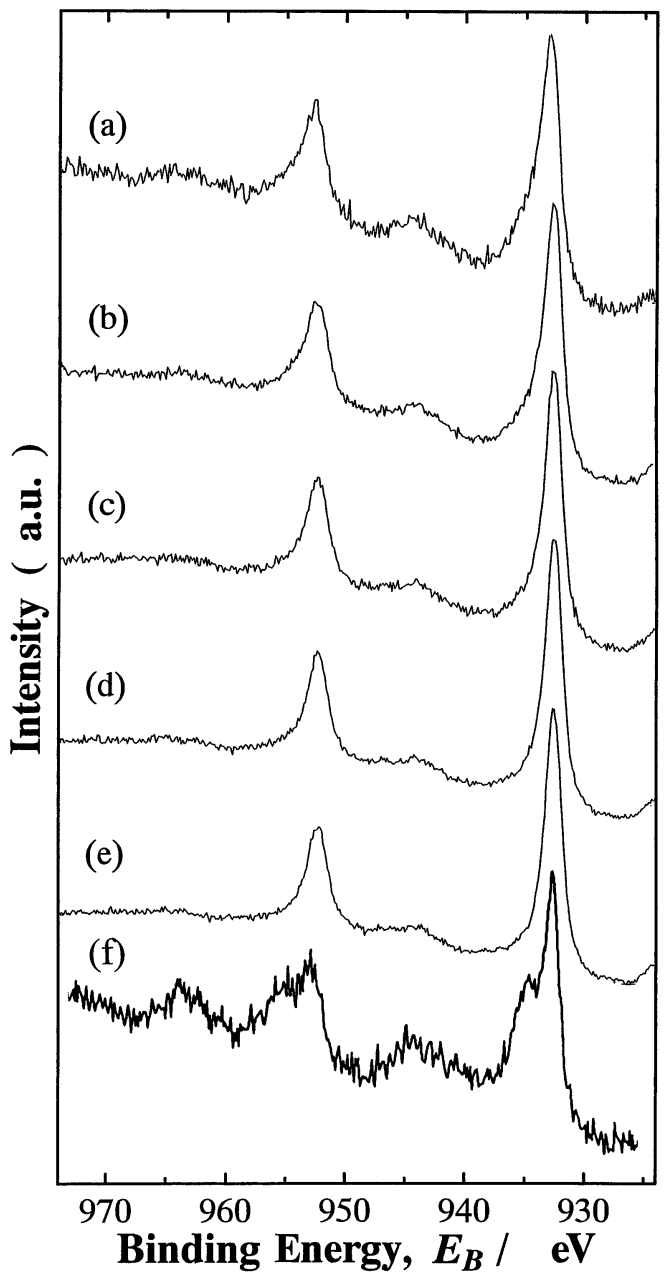

Fig. $4 \mathrm{Cu} 2 \mathrm{p}$ AR-XPS spectra obtained in the take-off angle of (a) $0.262 \mathrm{rad}$, (b) $0.524 \mathrm{rad,} \mathrm{(c)} 0.786 \mathrm{rad,} \mathrm{(d)} 1.05 \mathrm{rad}$ and (e) $1.31 \mathrm{rad}$ for $\mathrm{Cu}-0.4 \% \mathrm{Cr}$ exposed to air for $4.2 \times 10^{5} \mathrm{~s}$, and (f) $\mathrm{Cu} 2 \mathrm{p}$ XPS spectrum obtained in the small take-off angle of $0.262 \mathrm{rad}$ for pure $\mathrm{Cu}$ exposed to air for $4.2 \times 10^{5}$

posure. Figures 6(a), (b), (c), (d) and (e) show Cr 2p AR-XPS spectra obtained in the take-off angle of $0.262,0.524,0.786$, 1.05 and $1.31 \mathrm{rad}$ for $\mathrm{Cu}-0.4 \% \mathrm{Cr}$ with chromium segregation exposed to air for $4.2 \times 10^{5} \mathrm{~s}$. A Cr $2 \mathrm{p}$ XPS spectrum from metallic chromium, which is segregated on the sample surface, is shown in Fig. 6(f), for comparison. Since the $\mathrm{Cr} 2 \mathrm{p}_{3 / 2}$ peak positions of $\mathrm{Cr}^{0}$ and $\mathrm{Cr}^{3+}$ are 574.4 and $576.9 \mathrm{eV}$, respectively, ${ }^{11)}$ these results indicate that the most of chromium segregated on the sample surface are oxidized. However, a slight $\mathrm{Cr}^{0}$ peak seems to be observed in the $\mathrm{Cr} 2 \mathrm{p}_{3 / 2}$ XPS spectra measured at high take-off angle in the oxidized sample. The present authors maintain the view, from this result, that chromium segregated on the sample surface does not fully cover the copper surface with a simple layered structure, but heterogeneously present on the surface. Although no definite information about the atomic distribution or microscopic morphology of chromium segregated on the surface of $\mathrm{Cu}-$ $\mathrm{Cr}$ is available yet, the amount of segregated chromium is not enough high to reduce the growth of the native oxide layer. In addition, if chromium precipitates in the thin surface layer, e.g. in the island-like form, as discussed in the above section, such microscopic heterogeneity may reduce the effect of chromium on the native oxide layer. 


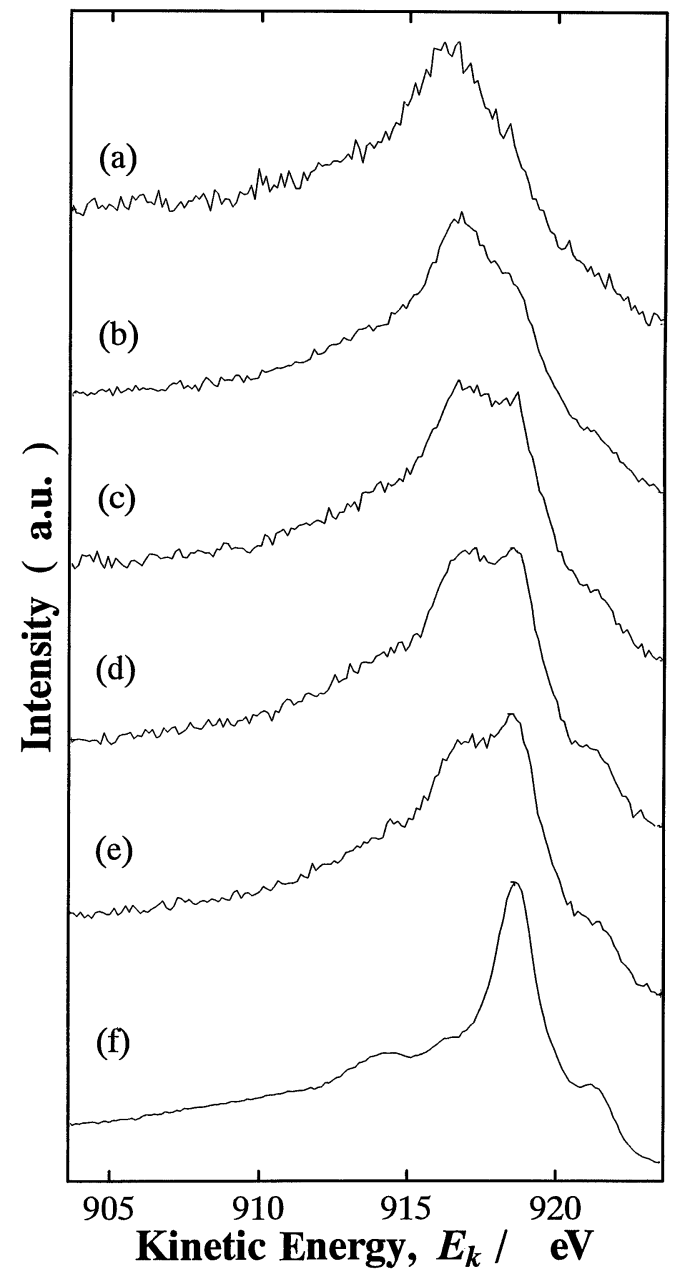

Fig. $5 \mathrm{Cu} \mathrm{L}{ }_{3} \mathrm{M}_{45} \mathrm{M}_{45}$ AR-XAES spectra obtained in the take-off angle of (a) $0.262 \mathrm{rad}$, (b) $0.524 \mathrm{rad}$, (c) $0.786 \mathrm{rad}$, (d) $1.05 \mathrm{rad}$ and (e) $1.31 \mathrm{rad}$ for $\mathrm{Cu}-0.4 \% \mathrm{Cr}$ exposed to air for $4.2 \times 10^{5} \mathrm{~s}$, and (f) $\mathrm{Cu} \mathrm{L}_{3} \mathrm{M}_{45} \mathrm{M}_{45}$ XAES spectrum for metallic copper.

\section{Concluding Remarks}

AR-XPS has been used for studying the surface segregation of chromium in a copper- $0.4 \%$ chromium alloy. The effect of chromium segregation on the formation of native oxide has also investigated in this alloy. The main results obtained in these experiments are as follows:

(1) The segregation of chromium up to about 15 at\% was found at the surface by annealing up to about $1000 \mathrm{~K}$ under ultra high vacuum, according to a simple layered model assuming thin homogeneous layers. The effective thickness of segregated layer was estimated to be about $0.8 \mathrm{~nm}$.

(2) The results of the sample surface with chromium segregation, which was exposed to air, showed that the segregated chromium does not significantly inhibit the growth of the native oxide of copper. The small effect of chromium segregation on the native oxide is considered to result from the relatively high oxidation rate of copper and the microscopic heterogeneity of segregated chromium.

\section{Acknowledgements}

The authors are grateful to Mr. T. Sato and Mr. M. Itoh for their help and maintenance of XPS apparatus.

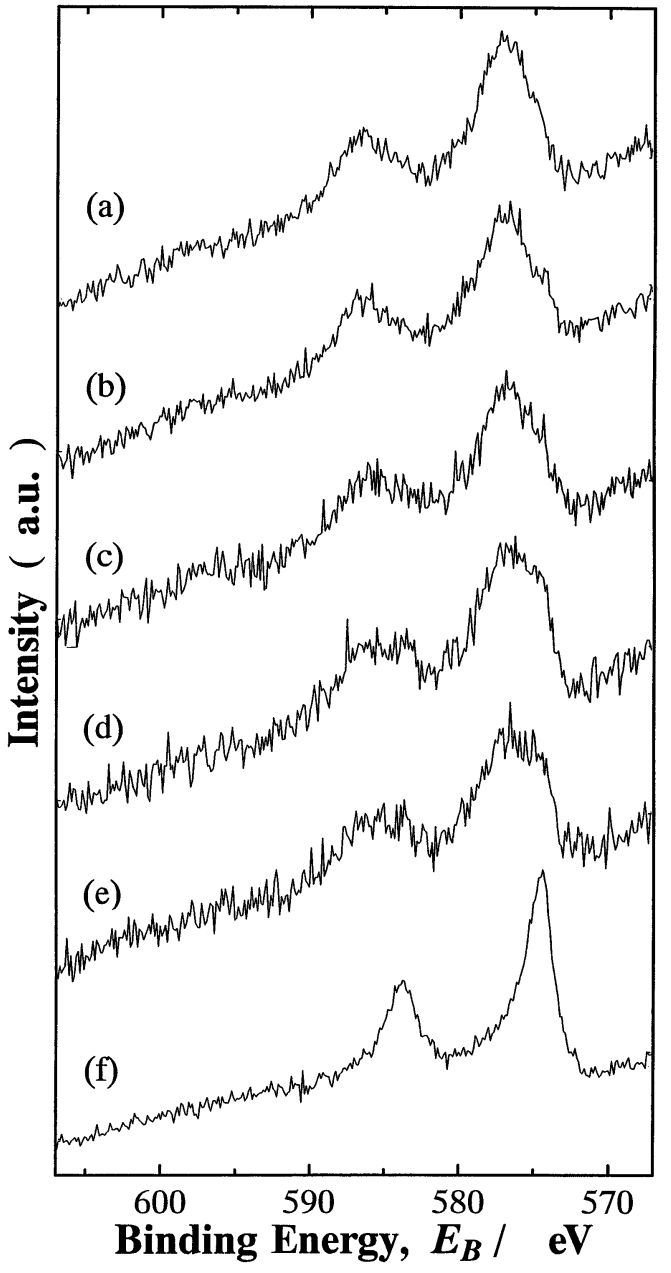

Fig. $6 \mathrm{Cr} 2 \mathrm{p}$ AR-XPS spectra obtained in the take-off angle of (a) $0.262 \mathrm{rad}$, (b) $0.524 \mathrm{rad}$, (c) $0.786 \mathrm{rad}$, (d) $1.05 \mathrm{rad}$ and (e) $1.31 \mathrm{rad}$ for $\mathrm{Cu}-0.4 \% \mathrm{Cr}$ exposed to air for $4.2 \times 10^{5} \mathrm{~s}$, and (f) $\mathrm{Cr} 2 \mathrm{p}$ XPS spectrum for metallic chromium segregated on the surface.

\section{REFERENCES}

1) S. K. Lahiri, N. K. Waalib Singh, K. W. Heng, L. Ang and L. C. Goh: Microelectronics Journal 28 (1998) 335-341.

2) S. J. Cho and K. W. Paik: Scr. Mater. 38 (1998) 1149-1154.

3) K. Chiang, T. A. Wallace and Clark: Surf. Coatings Tech. 86-87 (1996) 48-55.

4) T. Kekesi, K. Miura, Y. Ishikawa and M. Usshiki: Metall. Mater. Trans. B 28B (1997) 987-993.

5) S. Suzuki, Y. Ishikawa, M. Isshiki and Y. Waseda: Mater. Trans., JIM 38 (1997) 1004-1009.

6) S. Suzuki, T. Kosaka, H. Inoue, M. Isshiki and Y. Waseda: Appl. Surf. Sci. 103 (1996) 495-502.

7) S. Suzuki and Y. Waseda: Scr. Mater. 36 (1997) 915-920.

8) S. Suzuki, T. Kosaka, H. Inoue and Y. Waseda: Mater. Trans., JIM 36 (1995) 1379-1385.

9) S. Poulston, P. M. Parlett, P. Stone and M. Boweker: Surf. Interface Anal. 24 (1996) 811-818.

10) "Binary Alloy Phase Diagrams" Vol. 2, Ed. by T. Massalski (ASM International, Materials Park, 1990) p. 1266-1268.

11) J. F. Moudler, W. F. Sticle, P. E. Sobol and K. Bomben: X-ray photoelectron spectroscopy, (Physical Electronics, Minnesota, 1993). 